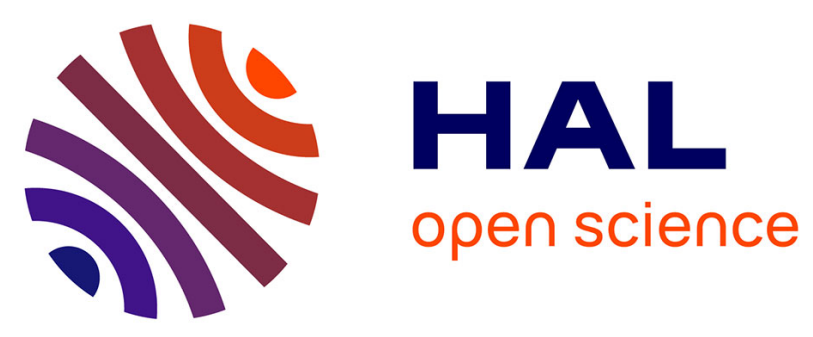

\title{
Eleostearic Phospholipids as Probes to Evaluate Antioxidants Efficiency against Liposomes Oxidation
}

Erwann Durand, André Delavault, Claire Bourlieu, Jérôme Lecomte, Bruno

Barea, Maria-Cruz Figueroa Espinoza, Eric A. Decker, Françoise Michel Salaun, Gilles Kergourlay, Pierre Villeneuve

\section{To cite this version:}

Erwann Durand, André Delavault, Claire Bourlieu, Jérôme Lecomte, Bruno Barea, et al.. Eleostearic Phospholipids as Probes to Evaluate Antioxidants Efficiency against Liposomes Oxidation. Chemistry and Physics of Lipids, 2017, 209, pp.19-28. 10.1016/j.chemphyslip.2017.10.006 . hal-01837483

\section{HAL Id: hal-01837483 \\ https://hal.science/hal-01837483}

Submitted on 25 May 2020

HAL is a multi-disciplinary open access archive for the deposit and dissemination of scientific research documents, whether they are published or not. The documents may come from teaching and research institutions in France or abroad, or from public or private research centers.
L'archive ouverte pluridisciplinaire HAL, est destinée au dépôt et à la diffusion de documents scientifiques de niveau recherche, publiés ou non, émanant des établissements d'enseignement et de recherche français ou étrangers, des laboratoires publics ou privés. 


\section{Accepted Manuscript}

Title: Eleostearic Phospholipids as Probes to Evaluate Antioxidants Efficiency against Liposomes Oxidation.

Authors: Erwann Durand, André Delavault, Claire Bourlieu, Jérôme Lecomte, Bruno Baréa, Maria Cruz Figueroa Espinoza, Eric A. Decker, Françoise Michel Salaun, Gilles

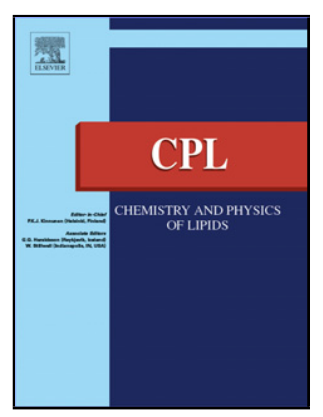

Kergourlay, Pierre Villeneuve

PII:

DOI:

Reference:

S0009-3084(17)30226-8 https://doi.org/10.1016/j.chemphyslip.2017.10.006

To appear in: $\quad$ Chemistry and Physics of Lipids

Received date: $\quad 22-8-2017$

Revised date: 21-9-2017

Accepted date: $\quad$ 19-10-2017

Please cite this article as: Durand, Erwann, Delavault, André, Bourlieu, Claire, Lecomte, Jérôme, Baréa, Bruno, Espinoza, Maria Cruz Figueroa, Decker, Eric A., Salaun, Françoise Michel, Kergourlay, Gilles, Villeneuve, Pierre, Eleostearic Phospholipids as Probes to Evaluate Antioxidants Efficiency against Liposomes Oxidation.Chemistry and Physics of Lipids https://doi.org/10.1016/j.chemphyslip.2017.10.006

This is a PDF file of an unedited manuscript that has been accepted for publication. As a service to our customers we are providing this early version of the manuscript. The manuscript will undergo copyediting, typesetting, and review of the resulting proof before it is published in its final form. Please note that during the production process errors may be discovered which could affect the content, and all legal disclaimers that apply to the journal pertain. 


\section{Eleostearic Phospholipids as Probes to Evaluate Antioxidants Efficiency against Liposomes Oxidation.}

Erwann Durand $^{1 *}$, André Delavault ${ }^{1}$, Claire Bourlieu ${ }^{2}$, Jérôme Lecomte ${ }^{1}$, Bruno Baréa ${ }^{1}$, Maria

Cruz Figueroa Espinoza ${ }^{3}$, Eric A. Decker ${ }^{4}$, Françoise Michel Salaun ${ }^{5}$, Gilles Kergourlay ${ }^{5}$, Pierre Villeneuve ${ }^{1}$

${ }^{1}$ CIRAD, UMR IATE, Montpellier F-34398, France

${ }^{2}$ INRA, UMR IATE, Montpellier F-34060, France

${ }^{3}$ Montpellier SupAgro, UMR IATE, Montpellier F-34060, France

${ }^{4}$ Food Chem. Dept., U. Mass., Amherst, MA, USA

${ }^{5}$ Diana Pet Food, ZA du Gohélis, 56250 ELVEN, France

*Corresponding author:

Dr. Erwann DURAND, CIRAD, UMR IATE, Montpellier

F-34398, France

E-mail address: erwann.durand@ cirad.fr

Tel: +33 (0)4 99612030

ORCID: 0000-0002-0306-8081 


\title{
Graphical abstract
}

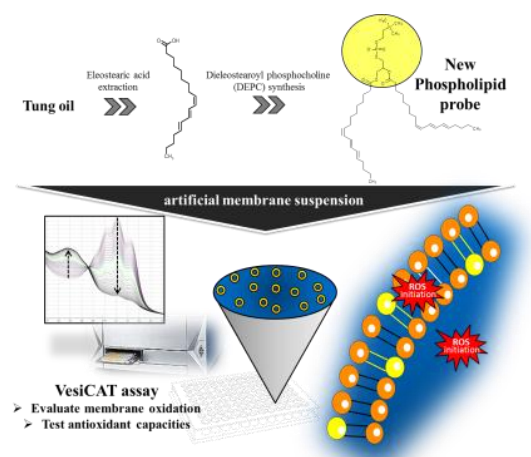

\section{Highlights}

- A new oxidation high-throughput assay based on the UV properties of a phospholipid probe is proposed.

- Two site of oxidation (membrane or aqueous phase) were developed.

- The new method, tested with several antioxidants, is rapid and reproducible.

- Aqueous or membrane-induced oxidations provide further information on the antioxidants efficacy.

\begin{abstract}
:
Regardless of the applications: therapeutic vehicle or membrane model to mimic complex biological systems; it is of a great importance to develop simplified, reproducible and rapid model assays allowing for a relevant assessment of the liposomal membrane oxidation and therefore antioxidant activity of selected molecules. Here, we describe a new and highthroughput assay that we called "Vesicle Conjugated Autoxidizable Triene (VesiCAT)". It is based on specific UV absorbance spectral properties of a new phospholipid probe, synthesized with natural conjugated eleostearic acid extracted from Tung oil. The VesiCAT assay has been developed with two different radical generators (2,2'-azobis(2-amidinopropane) dihydrochloride; AAPH and 2,2'-azobis(2,4-dimethylvaleronitrile); AMVN), producing a
\end{abstract}


constant flux of oxidant species, either in membrane or in aqueous phase. This method appears very efficient in assessing the effect of various pure antioxidant molecules in their ability to preserve liposomes from oxidative degradation. In addition, the AAPH- and AMVN-induced oxidations offer the possibility of extracting different but complementary information with respect to the antioxidants efficacy.

KEYWORDS: Eleostearic Phospholipid, Antioxidants, Vesicles, Liposomes, Lipid oxidation.

\section{INTRODUCTION}

Liposomes consist in spherical phospholipids vesicles which stabilize an aqueous core from the external medium ${ }^{1}$. Over the past decades, several commercial applications of liposomes have been developed to deliver bioactive molecules or therapeutic agents into their target zone of activity within organisms (e.g., cells, tissues) while improving clinical efficacy and limiting side effect linked to non-target delivery ${ }^{2}$. Modulation of liposome structure is easy since both the alkyl chains or polar heads of phospholipids can be tailored to modify vesicle size, charge but also membrane physical state or fluidity ${ }^{3}$. Liposomes present different physical structures that depend on their chemical composition and their method of preparation ${ }^{4}$. Multilamellar vesicles (MLV) contain several bilayers surrounding each other whereas unilamellar liposomes are made of a single bilayer. These latter can be distinguished as small unilamellar vesicles (SUV; diameter <100 nm) or large unilamellar vesicles (LUV; diameter >100 nm). Multi-vesicular vesicles (MVV) correspond to smaller vesicles trapped into a large vesicle. In the context of their use as bioactive delivery vehicles, liposomes exhibit drawbacks owing to their relative poor physical or chemical stability ${ }^{5}$. For example, depending on environmental conditions (e.g., temperature, ionic strength, $\mathrm{pH}$ ), they may undergo 
aggregation phenomena ${ }^{6}$. Similarly, liposomes are prone to chemical degradation mainly via oxidation of their fatty acid constitutive moieties. Despite the relative simplicity of liposomal lipids, oxidation mechanisms remain complex because they depend on the oxidation inducer, the antioxidant's partitioning and activity, but also on both the composition and physical properties of the liposomes ${ }^{7}$. For example, the size and number of layers in the liposome impact its stability ${ }^{3}$. Apparently, LUV maintain their structural integrity when exposed to reactive oxygen species (ROS) generated outside the bilayer (in aqueous media). LUV are more sensitive to oxidation than MLV and they avoid the problem of partial accessibility of the oxidation inducer to external lipid bilayer as in $\mathrm{MLV}^{7}$. The oxidation of liposomes can be limited using the same strategies that are employed for the protection of classical oils (made of triacylglycerols). Such strategies involve the limitation of high temperature, light or oxygen exposure, as well as the use of exogenous antioxidants that can act by various mechanisms (e.g., metal chelators or radical scavengers) ${ }^{8}$.

In addition to their therapeutic use, liposomes have been used extensively as models for in vitro lipid oxidation studies ${ }^{9}$. The involvement of oxidants in several pathological disorders, including cancer, diabetes, cardiovascular diseases, chronic inflammatory disease, postischaemic organ injury, neurodegenerative disorders, and xenobiotic/drug toxicity has been widely documented ${ }^{10-12}$. No matter how oxidation is involved in tissue injury in human disease (origin of the disease or simply produced during the development of the damage), the mimetic bilayer structure of liposome represents an interesting tool to investigate the antioxidant potential of a compound, as well as drug-membrane interaction.

In a complex system where liposomes are involved, either in food, cosmetic or pharmaceutical formulations, the efficiency of these antioxidants would be governed, not only by their chemical reactivity, but also by their interactions with other components and their localization in the concerned systems. In particular, the most efficient antioxidants will be the 
ones expressing the best capacity to locate in the close vicinity, or more specifically, in the phospholipid membrane of the liposome. In that context, relevant methods are needed to evaluate the efficiency of antioxidants for the protection of liposomes against oxidation. Typically, the majority of existing methods are based on the measurement of oxidation rate in the absence or presence of the tested antioxidant in experimental protocols where phospholipids oxidation is generally induced by radical initiator or metal, and oxidation is measured by quantifying lipids primary and/or secondary oxidation compounds. Many other methods use fluorescent probes to evaluate the extent of lipid peroxidation in liposomal systems. For example, Kuypers et al. (1987) ${ }^{13}$ demonstrated the advantages of using cisparinaric acid (9-cis,11-trans,13-trans,15-cis-octadecatetraenoic acid) as fluorescent probe. This fatty acid containing four conjugated double bonds exhibits high fluorescence properties ( $\lambda$ ex/em: $320 / 432 \mathrm{~nm}$ ), as well as high sensitivity to free radical attacks. The key point is that the fluorescence of cis-parinaric acid is irreversibly lost during its oxidation, so many tests have been developed using this substrate ${ }^{14}$. For example, Osaka et al. (1997) ${ }^{15}$ assessed the ability of amphotericin B to overcome peroxidation of cis-parinaric acid complexed in liposomes using lipophilic AMVN (2,2'-azobis (2,4-dimethylvaleronitrile)) azo initiator. Cisparinaric acid as probe is indeed attractive due to the fact that it can be anchored in membranes which have led to a good detection sensitivity of oxidative processes in these highly organized structures. However this probe has some drawbacks: it is air sensitive and photolabile and undergoes photodimerization under illumination, which can result in loss of fluorescence and overestimation of the extent of lipid peroxidation ${ }^{16}$. Moreover, the results can be biased if the interfering molecule absorbs all or part of the excitation and/or emission photons. Also, the fluorescence and absorption measurements of the polyene is particularly sensitive to environmental perturbations, such as static electric fields ${ }^{17}$. Moreover, it is 
unclear how this probe in its free fatty acid form could affect antioxidant effect due to its undefined membrane anchoring or because it may alter physical properties of membranes.

C11-BODIPY ${ }^{581 / 591}$ (4,4-difluoro-5-(4-phenyl-1,3-butadienyl)-4-bora-3a,4a-diaza-s-indacene3-undecanoic acid), initially developed by Naguib (1998) ${ }^{18}$, is another fluorescent probe that, once incorporated in liposomes, is extensively used as oxidizable substrate to evaluate lipid membrane peroxidation. This fluorescent fatty acid analog, which the BODIPY core is connected to a phenyl moiety via a conjugated diene, displays bright red fluorescence. This substrate is highly oxidizable by peroxyl radicals (ROO) and its oxidation leads to gradual extinction of the fluorescent signal. However, Huang et al (2002) ${ }^{19}$ showed that the C11BODIPY $^{581 / 591}$ probe could undergo photobleaching and lose $30 \%$ of its fluorescence in the absence of AMVN. This suggests that, like cis-parinaric acid, C11-BODIPY $581 / 591$ is photosensitive and should thus be taken into account. More recently, other probes corresponding to BODIPY conjugates of $\alpha$-tocopherol were also used to evaluate the activity of antioxidants in liposomes ${ }^{20,21}$. The mechanism of these probes relies on the reaction of the phenolic moiety of the probe with ROO resulting in enhanced fluorescence in comparison with classical BODIPY probes. Although all the probes mentioned above are widely used to assess antioxidant in liposomal systems, one can question the relevance of the obtained results since these probes are artificial molecules that are not encountered in living systems or formulations where liposomes are involved. In addition, most of the synthetic probes used to evaluate the antioxidant capacity (e.g., BODIPY and its derivatives, HDAF $(\text { hexadecanoylaminofluorescein) })^{22}$, DPH-PA (diphenylhexatriene propionic acid) ${ }^{23}$ ) have different lipophilic and charge properties, as a result different membrane affinity, mobility, location, and penetration depth, and therefore skew the antioxidant interpretation and correlation with biological cells. Accordingly, there is a need in developing new methods for 
the evaluation of antioxidant potency in liposomal media where the used probe would correspond to real phospholipids instead of artificial probes.

In 2008, our group has developed a new method to evaluate antioxidants capacity in oil-inwater emulsion, using Tung oil as oxidizable substrate which is particularly rich in trieleostearin ${ }^{24}$. Due to its conjugated triene, eleostearic acid exhibits a unique UV absorbance spectrum that is very convenient to estimate its oxidation rate by UV spectrophometry equipment (micro-plate reader). This method (CAT assay) is now used to assess the potential of natural antioxidants or plant extracts ${ }^{25,26}$, phenolipids ${ }^{27-29}$, synthetic antioxidants ${ }^{30}$ or essential oils ${ }^{31}$. More recently, this method was also adapted to the use of a lipophilic azo initiator, namely AMVN to compare the behavior of hydrophilic and lipophilic antioxidants ${ }^{32}$.

Herein, we propose a further version of this eleostearic-based emulsion assay, adapted to vesicle suspension. For this, an eleostearic phospholipid probe was synthesized, and its concentration in artificial membrane suspension was fine tuned in order to visualize its natural absorbance using microplate reader. Then, the conditions were established with the aim at promptly and efficiently probe the membrane oxidation by simply following the eleostearic phospholipid absorbance decay. Finally, this new method called "Vesicle Conjugated Autoxidizable Triene (VesiCAT)", was tested with addition of diverse antioxidants. Either in aqueous or membrane region, linear and reproducible responses over the concentration range were observed, with respect to liposomes induced peroxidation and antioxidant efficacy. 


\section{MATERIAL AND METHODS}

\section{Chemicals}

Tung oil from Aleurites fordii seeds (Tung oil, average MW=872 g/mol), phosphate buffer solution $\mathrm{pH} 7.2$ (PBS), PPyr32 (4-pyrrolidinopyridine) and DCC (N, N'dicyclohexylcarbodiimide) and all solvents (HPLC or analytical grade) were purchased from Sigma-Aldrich (Saint Quentin, France). 1,2-dipalmitoyl-sn-glycero-3-phosphocholine (DPPC) and 1,2-dilauroyl-sn-glycero-3-phosphocholine (DLPC) were purchased from Avanti (Alabama, USA). sn-Glycero-3-phosphocholine (GPC) was purchased from Larodan (Solna, Sweden). Trolox (97\%) was obtained from Acros Organic (Geel, Belgium). 2,2'-azobis(2amidinopropane) dihydrochloride (AAPH) and 2,2'-azobis (2,4-dimethylvaleronitrile) (AMVN) were obtained from Wako Chemical (Neuss, Germany). Studied antioxidants: gallic acid (99\%), chlorogenic acid (99\%), quercetin dihydrate (99\%) and rosmarinic acid (96\%) were all purchased from Sigma-Aldrich (USA).

\section{Extraction and purification of $\alpha$-eleostearic acid from Tung Oil.}

Eleostearic acid was isolated from Tung oil using a method adapted from ${ }^{33-35}$. Tung oil (34 g) and potassium hydroxide $(40.5 \mathrm{~g})$ were dissolved in absolute ethanol $(250 \mathrm{~mL})$ in a $500 \mathrm{~mL}$ round-bottom flask under an argon atmosphere in the dark. The reaction mixture was stirred and refluxed for $3 \mathrm{~h}$. The mixture was cooled to room temperature, to which $200 \mathrm{~mL}$ of distilled water was added, and the aqueous phase was washed three times with hexane $(3 \times$ $150 \mathrm{~mL})$. The aqueous phase was then acidified $(\mathrm{pH} \mathrm{2)}$ with sulfuric acid solution (50\% diluted, $9 \mathrm{M})$ and extracted three times with diethyl ether $(3 \times 200 \mathrm{~mL})$. The combined diethyl 
ether solution was dried over anhydrous sodium sulfate and evaporated to dryness under reduced pressure at $15^{\circ} \mathrm{C}$ in the dark (Buchi Rotavapor ${ }^{\circledR} \mathrm{R}-210$, Germany). The resulting eleostearic acid was purified by recrystallization. The crude powder obtained after evaporation was dissolved in acetone at room temperature and recrystallized twice at $-20{ }^{\circ} \mathrm{C}$. After vacuum filtration, a white powder of pure eleostearic acid (8.4 g) was obtained and dried under vacuum for further esterification. The product was identified by $1 \mathrm{D}$ NMR $(1 \mathrm{H}$ and 13C). 1H NMR (300 MHz, $\left.\mathrm{CDCl}_{3}\right): \delta 9.244(\mathrm{~s}, \mathrm{br}, 1 \mathrm{H}), 6.36-6.24(\mathrm{dd}, 1 \mathrm{H}), 6.12-5.97$ (q, 2H), 5.96-5.85 (dd, 1H), 5.68-5.56 (dt, 1H), 5.36-5.25 (dt, 1H), $2.30(\mathrm{t}, 2 \mathrm{H}), 2.16-2.01(\mathrm{~m}$, 4H), $1.60(\mathrm{q}, 2 \mathrm{H}), 1.41-1.20(\mathrm{~m}, 12 \mathrm{H}), 0.83(\mathrm{t}, 3 \mathrm{H}) \mathrm{ppm} .13 \mathrm{C} \mathrm{NMR}\left(75 \mathrm{MHz}, \mathrm{CDCl}_{3}\right): \delta$ $179.66(\mathrm{COOH}), 135.1-125.42(5 \mathrm{CH}), 33.8-22.1$ (10 CH2), 13.9 (1 CH3) ppm.

\section{Synthesis of 1,2- $\alpha$-Eleostearoyl-sn-glycero-3-phosphocholine (DEPC) adapted from ${ }^{36}$ :}

To a solution of sn-Glycero-3-phosphocholine (GPC) $(0.100 \mathrm{~g}, 0.4 \mathrm{mmol})$, pure $\alpha$-eleostearic acid (0.556 g, $2 \mathrm{mmol})$ was added, in alcohol-free and anhydrous $\mathrm{CHCl}_{3}(6 \mathrm{~mL})$, under stirring and inert atmosphere. A solution of freshly recrystallized PPyr32 (4pyrrolidinopyridine, $0.296 \mathrm{~g}, 2 \mathrm{mmol})$ and DCC (N, N'-dicyclohexylcarbodiimid, $0.388 \mathrm{~g}, 2$ $\mathrm{mmol}$ ), in $2 \mathrm{~mL}$ of $\mathrm{CHCl}_{3}$, was then added dropwise. After $24 \mathrm{~h}$ at $20^{\circ} \mathrm{C}$, the reaction mixture was filtered on a Sartorius mini-sart filter syringe $(0,45 \mu \mathrm{m})$, concentrated and re-diluted in $6 \mathrm{~mL}$ of ethanol/water $(9: 1 \mathrm{v} / \mathrm{v})$. Then, the product was purified, by HPLC semi-preparative chromatography (Thermo Ultimate 3000, Thermo Fisher Scientific, France) equipped with a fraction collector (AFC-3000), and a Hypersil Gold C18 column $(5 \mu \mathrm{m}, 175 \AA$, $21.2 \times 150$ $\mathrm{mm}$; Thermo Fisher Scientific, France). Flow rate and detection set at $20 \mathrm{~mL} / \mathrm{min}$ and 273 $\mathrm{nm}$, respectively. Eluent gradient was a binary mixture of $\mathrm{MeOH} / \mathrm{H}_{2} \mathrm{O}$, starting with $50 \%$ $\mathrm{MeOH}$ from 0 to $15 \mathrm{~min}$, then $100 \% \mathrm{MeOH}$ from 15 to $40 \mathrm{~min}$ ). Fractions containing the 
product were collected and this latter was identified by 1D NMR (1H and 13C) and 2D NMR (1H-1H and $1 \mathrm{H}-13 \mathrm{C}) .135 \mathrm{mg}$ of pure compound was obtained (45\% yield). ${ }^{1} \mathrm{H}$ NMR (300 $\left.\mathrm{MHz} \mathrm{CDCl}_{3}\right): \delta 0.87(\mathrm{t}, 6 \mathrm{H}, \mathrm{J}=6.9, \mathrm{C} 18-\mathrm{CH} 3, \mathrm{C} 36-\mathrm{CH} 3), 1.21-1.43(\mathrm{~m}, 24 \mathrm{H}, \mathrm{C}(4-7,16,17$, 22-25,34, 35)-CH2), 1.47-1.63 (m, 4H, C(3, 21)-CH2), 1.95-2.19 (m,8H, C(8, 15, 26, 33)-CH2), 2.22-2.29 (m, 4H C(2, 20)-CH2), 3.32 (s, 9H, N-(CH3)3), 3.68-3.83 (m, 2H, CH2-N), 3.84-3.99 (m, 2H, CH2 sn-3), 4.03-4.11 (m, 1H, CHsn-1), 4.22-4.42 (m, 3H, $\mathrm{PO}-\mathrm{CH} 2, \mathrm{CH}$ sn-1), 5.12-5.25 (m, 1H,CH sn-2) 5.31-5.40 (m, 2H C(9,27)-CH), 5.56-5.72 (m, 2H, C14, C32-CH), 5.92-6.17 (m,6H, C10, C11, C13, C28, C29, C31-CH), 6.30-6.38 (m, 2H,C12, C30-CH). 13C NMR (100 MHz CDCl 3$): \delta 14.1(\mathrm{C} 18,36), 22.4(\mathrm{C} 17,35), 25.1$ (C15, 33), 28.0 (C8, 26), 29.25,29.32, 29.41, 29.51, and 29.85 (C 4-7, 22-25), 31.7(C16,34), $32.7(\mathrm{C} 3,21), 34.3$ and $34.4(\mathrm{C} 2,20), 54.7(\mathrm{~N}(\mathrm{CH} 3) 3), 59.5(\mathrm{C}-\mathrm{N}, \mathrm{JC}-\mathrm{P}=5.1), 63.1(\mathrm{C}$ sn-1), $63.7(\mathrm{PO}-\mathrm{C}, \mathrm{JC}-\mathrm{P}=5.1), 66.6(\mathrm{C}$ sn-3, JC $-\mathrm{P}=6.6), 70.7(\mathrm{Csn}-2, \mathrm{JC}-\mathrm{P}=7.3), 126.0(\mathrm{C} 12$, 30), 128.9 (C10, 28), 130.7 (C13, 31), 131.9 (C9,27), 133.0 (C11, 29), 135.4 (C14, 32), 173.3 and $173.6(\mathrm{C} 1,19)$.

\section{Liposome oxidation assays with AAPH.}

Preparation of liposomes started by combining of $8 \mathrm{mg}$ of DPPC $\left(\mathrm{Tc}=42^{\circ} \mathrm{C}\right)$ or DLPC $(\mathrm{Tc}$ (phase transition temperature $\left.)=-1^{\circ} \mathrm{C}\right)$ and $0.8 \mathrm{mg}$ DEPC $(800 \mu \mathrm{L}$ from DEPC stock solution at $1 \mathrm{mg} \cdot \mathrm{mL}^{-1}$ in anhydrous $\left.\mathrm{CHCl}_{3}\right)$ in $\mathrm{CHCl}_{3}$. The mixture was put in a round bottom flask and the solvent was then slowly removed, in the dark, at room temperature by rotary evaporator to form a thin lipid layer at the bottom of the flask. The lipid film was kept under vacuum for $2 \mathrm{~h}$ to remove the solvent traces. The phospholipids were resuspended for $30 \mathrm{~min}$ with $10 \mathrm{~mL}$ of phosphate buffer (PBS, $\mathrm{pH}=7.2)$ at a temperature above the $\mathrm{Tc}\left(50^{\circ} \mathrm{C}\right.$ for DPPC, $20^{\circ} \mathrm{C}$ for DLPC) of the lipid. This suspension was sonicated in a bath sonicator ( $5 \mathrm{~min}$, 
$35 \mathrm{KHz}$, Transonic $\mathrm{T}$ 425/H, Elsloo, The Netherlands) and put back in the incubator for another $30 \mathrm{~min}$ of stirring and returned to the bath sonicator for an additional $15 \mathrm{~min}$. The suspension was subsequently subjected to 10 cycles of extrusion in an Avanti mini-extruder apparatus (Alabama, USA) with 100-nm polycarbonate filters. After extrusion, the $10 \mathrm{~mL}$ of liposomes were diluted with $10 \mathrm{~mL}$ of PBS. All liposome samples were freshly prepared the day of the experiments. Particle size distribution was assessed with a nanoparticle size analyzer (Nicomp N3000 DLS System, Port Richey, USA). The Dynamic Light Scattering analyses showed LUV to be monodisperse, with mean diameter $=133.8 \pm 20.6 \mathrm{~nm}$.

A total of $240 \mu \mathrm{L}$ of these suspensions was transferred to a 96-wells microplate (Greiner, Frickenhausen, Germany). For assays, the liposomes were treated with 0.5 to $4 \mu \mathrm{M}$ of antioxidant (30 $\mu \mathrm{L}$ from stock solution in PBS were added to the wells) and incubated with a control temperature at $34.5 \pm 0.5^{\circ} \mathrm{C}$ (microplate reader temperature setting at $40^{\circ} \mathrm{C}$ ). Finally, a total of $30 \mu \mathrm{L}$ of a solution of AAPH in PBS (20mM), prepared immediately before reading, was added to wells to induce oxidation. The progress of reactions was immediately monitored by recording the decrease in absorbance at $273 \mathrm{~nm}$. Measurements were performed every 2 min for $7.5 \mathrm{~h}$, with a $5 \mathrm{~s}$ agitation before each measure, using an Infinite M1000 microplate reader (TECAN, Gröedig, Austria) equipped with Magellan software. All measurements were performed in triplicate and reported as the average \pm standard deviation (SD).

\section{Liposome oxidation assays with AMVN.}

Preparation of liposomes started by dissolution of $16 \mathrm{mg}$ of DLPC $\left(\mathrm{Tc}=-1^{\circ} \mathrm{C}\right)$ and $0.8 \mathrm{mg}$ DEPC (800 $\mu \mathrm{L}$ from DEPC stock solution at $1 \mathrm{mg} \cdot \mathrm{mL}$ in anhydrous $\mathrm{CHCl}_{3}$ ), and $1.5 \mathrm{mg}$ of AMVN prepared in $2 \mathrm{~mL}$ of $\mathrm{CHCL}_{3}$, put in a round bottom flask and the solvent was then slowly removed at room temperature by rotary evaporator, to form a thin lipid layer at the 
bottom of the flask. The lipid film was kept under vacuum for $2 \mathrm{~h}$ to remove the solvent traces. The phospholipids were resuspended with $10 \mathrm{~mL}$ of $\mathrm{PBS}$ at $20^{\circ} \mathrm{C}(30 \mathrm{~min}$ in the incubator). This suspension was sonicated in a bath sonicator (5 min) and put back in the incubator for another $30 \mathrm{~min}$ of stirring and returned to the bath sonicator for an additional 15 min. The suspension was subsequently subjected to 10 cycles of extrusion in an Avanti miniextruder apparatus (Alabama, USA) with 100-nm polycarbonate filters. After extrusion, the $10 \mathrm{~mL}$ of liposomes were diluted with $10 \mathrm{~mL}$ of PBS. All liposome samples were freshly prepared the day of the experiments. Particle size distribution was assessed with a nanoparticle size analyzer (Nicomp N3000 DLS System, Port Richey, USA). The Dynamic Light Scattering analyses showed LUV to be monodisperse, with mean diameter $=132.3 \pm$ $11.3 \mathrm{~nm}$.

A total of $240 \mu \mathrm{L}$ of these suspensions was transferred to a 96-wells microplate. For assays, the liposomes were treated with 1 to $8 \mu \mathrm{M}$ of antioxidant $(60 \mu \mathrm{L}$ from stock solution in PBS were added to the wells). To induce oxidation, the temperature in the microplate wells was increased to $43 \pm 0.5{ }^{\circ} \mathrm{C}$ and the progress of reactions was immediately monitored by recording the decrease in absorbance at $273 \mathrm{~nm}$. Measurements were performed every 15 min for $7.5 \mathrm{~h}$ using an Infinite M1000 microplate reader equipped with Magellan software. An orbital agitation with a control temperature at $43 \pm 0.5^{\circ} \mathrm{C}$ in the microplate wells (temperature setting $47^{\circ} \mathrm{C}$, equipment) before each measure was performed using a Grant Bio PHMP thermoshaker for microplates. All measurements were performed in triplicate and reported as the average \pm SD.

\section{Expression of VesiCAT assay results:}


To normalize data, the raw absorbance signal was transformed in relative absorbance according to the Equation 1

Relative absorbance $=$ Abst $/$ Abs0

Where Abst and $\mathrm{Abs} 0$ are absorbances measured at times $t$ and 0 min, respectively. It is worth mentioning that if the measurement is not rapid enough after initiating the oxidation, the Abs0 for the blank (without antioxidant) may be lower than the sample containing the antioxidant. In this case, to normalize $\mathrm{Abs} 0$, the experimental $\mathrm{Abs} 0$ of blank can be artificially replaced with the Abs0 of samples in Equation (1). The area under curve (AUC) corresponding to relative absorbance decay was then calculated as follows

$\mathrm{AUC}=1+\mathrm{Abst} 1 / \mathrm{Abs} 0+\operatorname{Abs} 2 / \mathrm{Abs} 0 \ldots+\mathrm{Abs} 299 / \mathrm{Abs} 0 \ldots+\mathrm{Abs} 300 / \mathrm{Abs} 0$

The net protection area provided by an antioxidant sample was then calculated using the difference between the AUC in the presence of an antioxidant sample (AUC $\left.\mathrm{Aample}_{\text {e }}\right)$ and the AUC of the blank (AUC $\mathrm{Control}_{1}$, the latter consisting of the same mixture without antioxidant. Trolox was used as a calibrator for antioxidant capacity measurements. Thus, the antioxidant capacity of a sample relative to Trolox (VesiCAT value) is given as:

VesiCAT value $=\left[\left(\mathrm{AUC}_{\text {Sample }}-\mathrm{AUC}_{\text {Control }}\right) /\left(\mathrm{AUC}_{\text {Trolox }}-\mathrm{AUC}_{\text {Control }}\right)\right] \mathrm{x}[($ moles of Trolox/moles of sample)]

A VesiCAT value was calculated for both AAPH- and AMVN-induced oxidation. Regarding the AMVN-induced oxidation, $\mathrm{AUC}_{80}$ corresponding to the area under the curve obtained after $80 \%$ of DEPC oxidation was calculated. The net protection area provided by the antioxidants and the VesiCAT values were calculated in the same way using equations (2) and (3). 


\section{RESULTS AND DISCUSSION}

\section{1: Description of the methodology}

Method development for evaluation of the antioxidant properties of molecules or extracts is of a great challenge. Indeed, it is very important for both industrial and academic prospects, to implement relevant, rapid, easy, and reliable assay. Here, we describe a new and highthroughput assay that we called "Vesicle Conjugated Autoxidizable Triene (VesiCAT)", based on the spectral properties of conjugated fatty acid naturally present in Tung oil. The strategy consisted of synthesizing a phospholipid containing eleostearic acid (an octadecatrienoic acid with a conjugated triene).

For this, a two-steps procedure (Figure. 1) was applied to the synthesis of a phosphatidylcholine having two eleostearic alkyl chains: first, the extraction and purification by recrystallization of the eleostearic acid from Tung oil ${ }^{35}$, and, second, phospholipid synthesis through nucleophilic substitution using sn-glycero-3-phosphocholine ${ }^{36}$. The soobtained di-eleostearic phospholipid (DEPC) was then used as new marker to assess oxidation once incorporated into model membrane systems (liposomes). Indeed, the conjugated trienes bound onto the phosphocholine moiety exhibit very high oxidative sensitivity and strong absorption in the ultraviolet domain characterized by a signal having three peaks at 263, 273, and $283 \mathrm{~nm}$ (Figure. 2). Under oxidizing conditions induced by a hydrophilic peroxyl radical

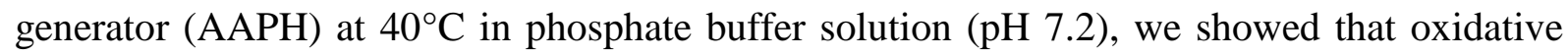
degradation of such liposomes enriched in DEPC probe, could be kinetically followed by measurement of the absorbance decrease at $273 \mathrm{~nm}$ (Figure 2). Concomitantly, an increase in absorbance at around $230 \mathrm{~nm}$ was also observed due to oxidative degradation of the conjugated trienes system to conjugated dienes ${ }^{24,37}$. 
We also studied the natural oxidation of the DEPC in a liposomal system in the absence of azo initiator (data not shown). However, we observed that oxidation kinetics were much slower ( days) than artificially induced oxidation ( hours), which appears to be incompatible with high-throughput purpose. That is why the use of azo initiators was chosen. Indeed, despite their artificiality, they are easy to use, enabling a constant, fast, and temperaturecontrolled rate of peroxidation. Two different radical generators (namely AAPH (hydrophilic) and AMVN (lipophilic)) were used with the aim at comparing water-soluble and interface membrane radical initiation. We first adjusted the main parameters (e.g., oxidizing conditions, liposome preparation, DEPC concentration), and then validated the method by using some phenolic antioxidants.

\section{VesiCAT assay development and validation with antioxidants}

VesiCAT with water radical initiation $(A A P H)$

The method was developed with the simplest liposomal system, made with non-oxidizable phospholipids having different alkyl chain lengths, namely DLPC and DPPC. For this, two different large unilamellar vesicles, prepared with a blend of DEPC/DLPC and DEPC/DPPC, were made to evaluate how membrane structure can affect the kinetics of oxidation and antioxidant response. Liposomes suspensions were oxidized at $34.5 \pm 0.5{ }^{\circ} \mathrm{C}$ (liquid temperature in wells) with a constant flux of radical initiators generated in the aqueous phase by thermo degradation of AAPH. For this, the AAPH concentration was fixed at $2 \mathrm{mM}$, which represents a good compromise between the oxidation rate and the substrate/azo initiator ratio. 
Dotted lines Figures. 3 and $\mathbf{4}$ show the results of DEPC oxidation experiments carried out in DLPC or DPPC model membranes, respectively. A mass ratio of 1:10 DEPC to other phospholipids allowed for the best condition to observe a linear absorbance related to its concentration. The results indicated that the DEPC oxidation kinetic in DLPC or DPPC membranes is almost the same, with $50 \%$ of the DEPC being oxidized after $34.5 \pm 4.9$ min and $32 \pm 5.1 \mathrm{~min}$, in DLPC and DPPC respectively. Overall, the VesiCAT assay validation consisted of verifying whether the addition of an antioxidant compound resulted in a delay in oxidation of the model liposomes, which could be spectrophotometrically evaluated by monitoring the decay in absorbance at $273 \mathrm{~nm}$. First, Trolox (water-soluble analog of $\alpha$ tocopherol) was used as a reference standard similarly to what we did previously when developing the CAT assay ${ }^{21}$. Its addition at different concentrations (from 0.5 to $8 \mu \mathrm{M}$ ) in liposome suspensions before initiating oxidation with AAPH led to an expected, and a desired, progressive delay in the absorbance decay (Figures. 3 and 4).

Many strategies could be used to measure and represent the antioxidant capacity such as: the area under the curve (AUC), the reaction rate with free radicals, the inhibition time, and the antioxidant concentration necessary to achieve 50\% inhibition (IC50). A good method should be able to differentiate the antioxidants with different reaction kinetics. Measurement of the AUC seems more suitable when the objective is to compare antioxidant capacity of various molecules/extracts, independently of the antioxidative mechanism (i.e., retarder or chain breaker). Indeed, for methods using a fixed time or inhibition degree as endpoint, the time or inhibition degree selection is critical to evaluate antioxidant efficacy. Different time points or 
different inhibition degrees may provide different antioxidant values (even change the ranking) because any activity of the reaction after the fixed point is totally overlooked ${ }^{38}$. However, for methods utilizing AUC, there is a clear starting point and a clear endpoint, and its calculation exploits both inhibition time and degree of oxidation, thus reflecting the different reaction kinetics. From those reasons, we believe that assays using AUC provide global information, whereas other approaches may give more specific data. However, kinetic parameters such as lag phase duration and initial rate can be also evaluated to get more insight on the oxidation mechanisms.

In the AAPH-induced oxidations, the net protection $\mathrm{AUC}$ of the reference $\left(\mathrm{AUC}_{\mathrm{Trolox}}-\right.$ AUC $\left._{\text {Control }}\right)$ versus concentration, allowed for a perfect linear relationship $\left(\mathrm{R}^{2} \geq 0.997\right)$, with values equivalent to 9.8 -fold \pm 0.4 the Trolox concentration in DEPC/DLPC (Figure. 3) and 8.3-fold \pm 0.5 the Trolox concentration in DEPC/DPPC membranes (Figure. 4). In addition, various antioxidants at different concentrations were tested in the different membrane composition (Figures. 3 and 4). These model antioxidants were chosen according to their occurrence in the literature dealing with antioxidant behaviors and also on the fact that they cover different chemical structures from simple phenolic compounds to more complex molecules. Through calculation of the AUC, good linear relationships $\left(R^{2} \geq 0.98\right)$ were established between net protection areas $\left(\mathrm{AUC}_{\text {Antioxidants }}-\mathrm{AUC}_{\mathrm{Control}}\right)$ and antioxidant concentrations for all phenolics tested, both in DLPC (Figure. 5) and DPPC (Figure. 6) vesicles.

Thus, regardless of the nature of the antioxidants and membrane composition, the oxidation of the phospholipid follows very similar and consistent trend. It is worth noting that the higher 
the leading coefficient of the linear function represented by the net protection versus antioxidant concentration, the better the antioxidant capacity is. Thus, rosmarinic acid showed the best antioxidant ability over the rest of the molecules. The results are not very surprising because this compound has been already attested to be an efficient antioxidant whether in formulated lipid dispersions or homogenous systems ${ }^{24,39}$. Its strong antioxidant capacity is often correlated with its two catechol functions. On the contrary, gallic acid presented the lowest efficiency, whereas chlorogenic acid and quercetin exhibited very similar protection effect. Here, the antioxidant capacity is the result of the scavenging/reducing free radicals properties of molecules, but also of their capacity to alter the reactive oxygen species propagation from the fatty acids within the membranes. It is worth noting that the main purpose of this article is not to compare and discuss about the antioxidant effects, but rather to describe the new method. Nevertheless, it is necessary to recognize that the method exposes predictable antioxidant ranking for such experiments with rosmarinic acid > quercetin chlorogenic acid > gallic acid, in accordance with theoretical expectations, because of the number and position of the hydroxyl groups as well as the degree of conjugation of the whole molecule ${ }^{40,41}$.

\section{VesiCAT with membrane radical initiation (AMVN)}

The same approach was performed using liposoluble AMVN as azo initiator. AMVN is a synthetic azo-compound that dissociates to form $\mathrm{C}$-centered free radicals and then peroxyl radicals by oxygen reaction, in the hydrophobic phospholipid bilayer. Unlike water-based initiators, AMVN must be added before vesicles formation. For that reason, the VesiCAT method was described with DLPC membranes, where the lower liquid-crystalline phase transition temperature than DPPC allowed preparing of LUV at low temperatures $\left(20^{\circ} \mathrm{C}\right)$ without triggering AMVN radical production and initiation of fatty acid oxidation. Liposome 
suspensions were oxidized at $43 \pm 0.5^{\circ} \mathrm{C}$ (liquid temperature in wells) with a constant flux of radical initiators generated in the membrane bilayer by thermo degradation of AMVN. Dotted lines Figure. 7 show the result of DEPC oxidation carried out with a mass ratio DEPC to DLPC of 1:20, suitable to observe a linear absorbance related to concentration. In these conditions, $50 \%$ of the probe was oxidized after $48.5 \pm 4.9 \mathrm{~min}$.

As previously for AAPH induced oxidation, Trolox was used as a reference standard, and its addition at different concentrations (from 0.5 to $5 \mu \mathrm{M}$ ) in the LUV suspension before starting oxidation by increasing temperature, led to the same observation with a progressive delay in the absorbance decay (Figure. 7). However, in the oxidation experiments carried out with AMVN, the kinetic behavior, especially the very slow return to baseline, was different making the calculation of the total AUC more difficult. This is possibly the result of more complex reactivity between antioxidants and oxidant species, with a higher order reaction rate than the ones obtained in the AAPH assays. Thus, for AMVN-induced oxidation, the $\mathrm{AUC}_{80}$ corresponding to the area under the curve obtained after $80 \%$ of DEPC oxidation was calculated. In this condition, the net protection $\mathrm{AUC}_{80}$ of the reference $\left(\mathrm{AUC}_{80} \mathrm{Trolox}_{-}\right.$ AUC $80 \_$Control) versus concentration, allowed for a perfect linear relationship $\left(\mathrm{R}^{2} \geq 0.998\right)$, with values equivalent to 3.4 -fold \pm 0.6 the Trolox concentration in DEPC/DLPC membranes (Figure. 7). From a kinetic standpoint, Trolox exhibited different behaviors in both oxidation assays. It essentially showed inhibition of probe degradation in the AMVN-induced oxidation, with an insignificant oxidation lag phase. Conversely, in AAPH-induced oxidation, Trolox exhibited an oxidation lag phase proportionate to its concentration. Very similar observation has been made by Panya and co-workers while comparing oxidation after lipid or aqueous phase induction in Tung oil in water emulsion ${ }^{32}$. The same antioxidants were tested at different concentrations to prevent DEPC oxidative degradation by means of AMVN-induced 
oxidation (Figure. 7). Through calculation of the $\mathrm{AUC}_{80}$, good linear relationships $\left(R^{2} \geq 0.98\right)$ were established between net areas at $80 \%$ of DEPC oxidation (AUC 80 _AntioxidantAUC 80 Control) and antioxidant concentrations (Figure. 8). Unlike the AAPH-induced oxidation, Trolox appeared to be the best antioxidant. Contrariwise, chlorogenic acid showed the poorest antioxidant efficacy, whereas it was one of the best ones with AAPH assays.

VesiCAT assays: comparison of the results

It appears that the order of effectiveness of the AAPH-induced oxidation assays is gallic acid $<$ Trolox $<$ quercetin $\sim$ chlorogenic acid $<$ rosmarinic acid, whereas it is chlorogenic acid $<$ gallic acid < quercetin < rosmarinic acid < Trolox for AMVN-induced oxidations. When the equation (3) provided in material and methods section is applied, rosmarinic acid exhibited the highest VesiCAT value in all assays, followed by quercetin, whereas gallic acid showed very low values (Table. 1). As already mentioned, chlorogenic acid showed very opposite trends with respect to antioxidant capacity. It is an efficient antioxidant with aqueous generated oxidants, but poor antioxidant while oxidant species are generated in membrane domain. This is the perfect example that the effectiveness of antioxidants could be related to the type of inducer and the region where oxidant species are initiated and spread. Beside the membrane composition effect, the antioxidant capacity of molecules may result not only on their chemical interaction with other molecules involved in the oxidation pathway, but also on their location, concentration, distribution into the different regions (e.g., interfacial lipid membranes, water), or even penetration depth in membrane ${ }^{42}$. In addition, another fundamental facet to consider is the mobility of antioxidants in such assays monitored over few hours. When an antioxidant is added to the liposomal suspension, it will move to 
interfacial lipid membrane to reach its equilibrium distribution between interface and water phases. However, depending on the nature of antioxidant, this kinetic process (and equilibrium constant) may be significantly different and sometimes not fully resolved within the lifetime of the experiment.

A striking example to understand how the distribution affects the results is the important difference that may be observed in antioxidant responses in liposome assays, if antioxidants are blended with phospholipid before vesicles formation or added after. Indeed, it is different if the antioxidant has to move from dispersed liposome (core or interface) to dispersion water phase, or the reverse. Thus, the combination between mobility and equilibrium constant distribution has to be considered. In addition, one should keep in mind that all these phenomena explained with the parent antioxidant molecules, are also true with the daughter antioxidant molecules (oxidized antioxidants), introducing another complexity in the antioxidant interpretation due to the different chemico-physical properties of the newlyformed molecule. Overall, the VesiCAT method, developed with the two main different sites of oxidation (membrane and aqueous) provides consistent results and additional details. In this VesiCAT method, AMVN assays seem to provide more information about the molecule distribution and mobility toward the membrane region, whereas AAPH experiments would give more information about scavenging/reducing free radicals ability. In the light of the aforementioned statement, one may say that among the tested antioxidants, rosmarinic acid is the best one to scavenge/reduce free radical (VesiCAT values (TE) > 4, in the AAPH assays); chlorogenic acid and quercetin have intermediate efficiencies (VesiCAT values (TE) 2.5, in the AAPH assays); whereas gallic acid has the lowest value (VesiCAT values (TE) $<1$, in the AAPH assays). In addition, Trolox seems to have the best mobility and/or distribution in membrane, since it showed a low antioxidant efficacy in the AAPH assays, but the highest net protection in AMVN assay. Conversely, chlorogenic acid, which is quite a good radical 
scavenger/reducer of free radicals (AAPH assays), is very poor in the AMVN assay. One reason could be a slow mobility combined, or not, with a low distribution in the interfacial domain.

\section{CONCLUSION}

This study describes a new absorbance probe-based method (VesiCAT) for measuring liposome oxidation. The di-eleostearic phospholipid (DEPC) probe was synthesized through a two-steps procedure, and the experimental conditions were finely tuned to observe and measure its oxidation in liposomal systems. This is very unique system, and the big advantage over the other artificial probes is that the probe corresponds to real phospholipids. Indeed, the current probes used to evaluate the antioxidant capacity have different lipophilic and charge properties, and when blending with membrane, they could alter physical properties. In addition, their membrane affinity, mobility, location, penetration depth, and orientation are uncertain and would likely be different to a fatty acid esterified on a phospholipid. All these characteristics are essential while measuring antioxidant activity and therefore, imprecisions could misinterpret the antioxidant responses.

Considering that the region of oxidation may induce different oxidation pathways and therefore antioxidant responses, two inducers, with opposed solubility, were implemented to initiate oxidation. Results, carried out on several antioxidants, showed that the assays are reproducible and efficient, and pointed out that the AAPH- and AMVN-induced oxidations provide further information on the antioxidants efficacy. Moreover, methods were developed with liposomes made with DLPC or DPPC, but the new DEPC probe could also be combined with more complex membrane composition or different types of vesicles. 


\section{REFERENCES}

(1) Bangham, A. D.; Standish, M. M.; Watkins, J. C. Diffusion of univalent ions across the lamellae of swollen phospholipids. J. Mol. Biol. 1965, 13 (1), 238-252.

(2) Fan, Y., Zhang, Q. Development of liposomal formulations: From concept to clinical investigations. Asian J. Pharm. Sci. 2013, 8 (2), 81-87.

(3) Akbarzadeh, A.; Rezaei-Sadabady, R.; Davaran, S.; Joo, S. W.; Zarghami, N.;

Hanifehpour, Y.; Samiei, M.; Kouhi, M.; Nejati-Koshki, K. Liposome: classification, preparation, and applications. Nanoscale Res. Lett. 2013, 8 (1), 102.

(4) McClements, D. J. Encapsulation, protection, and release of hydrophilic active components: Potential and limitations of colloidal delivery systems. Adv. Colloid Interface Sci. 2015, 219, 27-53.

(5) Maherani B, Arab-Tehrany E, MozafariMR, Gaiani C, L. M. Liposomes: a review of manufacturing techniques and targeting strategies. Curr. Nanosci. 2011, 211 (7), 436452.

(6) Taylor, T. M.; Weiss, J.; Davidson, P. M.; Bruce, B. D. Liposomal Nanocapsules in Food Science and Agriculture. Crit. Rev. Food Sci. Nutr. 2005, 45 (7-8), 587-605.

(7) Schnitzer, E.; Pinchuk, I.; Lichtenberg, D. Peroxidation of liposomal lipids. Eur. Biophys. J. 2007, 36 (4-5), 499-515.

(8) Waraho, T.; McClements, D. J.; Decker, E. A. Mechanisms of lipid oxidation in food dispersions. Trends Food Sci. Technol. 2011, 22 (1), 3-13.

(9) Reis, S., Lucio, M., Segundo, M., \& Lima, J. L. F. C. Liposomes: Methods and protocols, Volume 2: Biological Membrane Models. In Springer Protocols; Weissig, 
V., Ed.; 2010; pp 167-188.

(10) Ziech, D.; Franco, R.; Georgakilas, A. G.; Georgakila, S.; Malamou-Mitsi, V.;

Schoneveld, O.; Pappa, A.; Panayiotidis, M. I. The role of reactive oxygen species and oxidative stress in environmental carcinogenesis and biomarker development. Chem.

Biol. Interact. 2010, 188 (2), 334-339.

(11) Jellinger, K. A. Basic mechanisms of neurodegeneration: a critical update. J. Cell. Mol. Med. 2010, 14 (3), 457-487.

(12) Bergamini, C. M.; Gambetti, S.; Dondi, A.; Cervellati, C. Oxygen, reactive oxygen species and tissue damage. Curr. Pharm. Des. 2004, 10 (14), 1611-1626.

(13) Kuypers, F. A.; Berg, J. J. M. van den; Schalkwijk, C.; Roelofsen, B.; Op den Kamp, J. A. F. Parinaric acid as a sensitive fluorescent probe for the determination of lipid peroxidation. Biochim. Biophys. Acta - Lipids Lipid Metab. 1987, 921 (2), 266-274.

(14) Tsuchiya M, Kagan VE, Freisleben H-J, Manabe M, P. L. Antioxidant activity of $\alpha$ tocopherol, $\beta$-carotene, and ubiquinol in membranes: cis-parinaric acid-incorporated liposomes. Methods Enzym. 1994, 234, 371-383.

(15) Osaka K, Ritov VB, Bernardo JF, Branch RA, K. V. Amphotericin B protects cisparinaric acid against peroxyl radicalinduced oxidation: amphotericin B as an antioxidant. Antimicrob Agents Chemother. 1997, 41, 743-747.

(16) Morgan C. G, Hudson B, Wolber P. K. Photochemical dimerization of parinaric acid in lipid bilayers. Proc. Natl. Acad. Sci. 1980, 77, 26-30.

(17) Sklar, L. A; Hudson, B. S.; Simoni, R. D. Conjugated polyene fatty acids as fluorescent probes: synthetic phospholipid membrane studies. Biochemistry. 1977, 16 (5), 819- 
828.

(18) Naguib, Y. M. A. A Fluorometric Method for Measurement of Peroxyl Radical Scavenging Activities of Lipophilic Antioxidants. Anal. Biochem. 1998, 265 (2), 290298.

(19) Huang, D.; Ou, B.; Hampsch-Woodill, M.; Flanagan, J. A.; Deemer, E. K.

Development and validation of oxygen radical absorbance capacity assay for lipophilic antioxidants using randomly methylated beta-cyclodextrin as the solubility enhancer. $J$. Agric. Food Chem. 2002, 50 (7), 1815-1821.

(20) Krumova, K.; Friedland, S.; Cosa, G. How Lipid Unsaturation, Peroxyl Radical Partitioning, and Chromanol Lipophilic Tail Affect the Antioxidant Activity of $\alpha$ Tocopherol: Direct Visualization via High-Throughput Fluorescence Studies Conducted with Fluorogenic $\alpha$-Tocopherol Analogues. J. Am. Chem. Soc. 2012, 134 (24), 10102-10113.

(21) Li, B.; Harjani, J. R.; Cormier, N. S.; Madarati, H.; Atkinson, J.; Cosa, G.; Pratt, D. A. Besting Vitamin E: Sidechain Substitution is Key to the Reactivity of Naphthyridinol Antioxidants in Lipid Bilayers. J. Am. Chem. Soc. 2013, 135 (4), 1394-1405.

(22) Santos, F.; Teixeira, L.; Lúcio, M.; Ferreira, H.; Gaspar, D.; Lima, J. L. F. C.; Reis, S. Interactions of sulindac and its metabolites with phospholipid membranes: An explanation for the peroxidation protective effect of the bioactive metabolite. Free Radic. Res. 2008, 42 (7), 639-650.

(23) Lúcio, M.; Nunes, C.; Gaspar, D.; Ferreira, H.; Lima, J. L. F. C.; Reis, S. Antioxidant activity of vitamin E and Trolox: Understanding of the factors that govern lipid peroxidation studies in Vitro. Food Biophys. 2009, 4 (4), 312-320. 
(24) Laguerre, M.; López-Giraldo, L. J.; Lecomte, J.; Baréa, B.; Cambon, E.; Tchobo, P. F.; Barouh, N.; Villeneuve, P. Conjugated autoxidizable triene (CAT) assay: a novel spectrophotometric method for determination of antioxidant capacity using triacylglycerol as ultraviolet probe. Anal. Biochem. 2008, 380 (2), 282-290.

(25) Durand, E.; Lecomte, J.; Upasani, R.; Chabi, B.; Bayrasy, C.; Baréa, B.; Jublanc, E.; Clarke, M. J.; Moore, D. J.; Crowther, J.; Wrutniak-Cabello, C; Villeneuve, P. Evaluation of the ROS Inhibiting Activity and Mitochondrial Targeting of Phenolic Compounds in Fibroblast Cells Model System and Enhancement of Efficiency by Natural Deep Eutectic Solvent (NADES) Formulation. Pharm. Res. 2017.

(26) Laguerre, M.; López Giraldo, L. J.; Piombo, G.; Figueroa-Espinoza, M. C.; Pina, M.; Benaissa, M.; Combe, A.; Rossignol Castera, A.; Lecomte, J.; Villeneuve, P. Characterization of Olive-Leaf Phenolics by ESI-MS and Evaluation of their Antioxidant Capacities by the CAT Assay. J. Am. Oil Chem. Soc. 2009, 86 (12), 12151225.

(27) Grajeda-Iglesias, C.; Salas, E.; Barouh, N.; Baréa, B.; Panya, A.; Figueroa-Espinoza, M. C. Antioxidant activity of protocatechuates evaluated by DPPH, ORAC, and CAT methods. Food Chem. 2016, 194, 749-757.

(28) Sørensen, A. M.; Durand, E.; Laguerre, M.; Bayrasy C.; Lecomte J.; Villeneuve P.; Jacobsen C. Antioxidant Properties and E ffi cacies of Synthesized Alkyl Ca ff eates, Ferulates, and Coumarates. J. Agric. Food Chem. 2014, 62 (52), 12553-12562.

(29) Laguerre, M.; López Giraldo, L. J.; Lecomte, J.; Figueroa-Espinoza, M.-C.; Baréa, B.; Weiss, J.; Decker, E. A.; Villeneuve, P. Relationship between hydrophobicity and antioxidant ability of "phenolipids" in emulsion: a parabolic effect of the chain length of rosmarinate esters. J. Agric. Food Chem. 2010, 58 (5), 2869-2876. 
(30) Zago, E.; Durand, E.; Barouh, N.; Lecomte, J.; Villeneuve, P.; Aouf, C. Synthesis of Lipophilic Antioxidants by a Lipase-B-Catalyzed Addition of Peracids to the Double Bond of 4-Vinyl-2-methoxyphenol. J. Agric. Food Chem. 2015, 63 (41), 9069-9075.

(31) Tchobo, F. P.; Alitonou, G. A.; Soumanou, M. M.; Barea, B.; Bayrasy, C.; Laguerre, M.; Lecomte, J.; Villeneuve, P.; Souhounhloue, K. C. D. Chemical Composition and Ability of Essential Oils from Six Aromatic Plants to Counteract Lipid Oxidation in Emulsions. J. Am. Oil Chem. Soc. 2014, 91 (3), 471-479.

(32) Panya, A.; Temthawee, W.; Phonsatta, N.; Charoensuk, D.; Deetae, P.; Visessanguan, W.; Decker, E. A. Apolar Radical Initiated Conjugated Autoxidizable Triene (ApoCAT) Assay: Effects of Oxidant Locations on Antioxidant Capacities and Interactions. J. Agric. Food Chem. 2015, 63 (34), 7546-7555.

(33) Nicolet, B. H. C18 Fatty Acids. I. the Non-Identity of Eleostearic Acid Tetrabromide From Tung Oil With Ordinary Linolic Acid Tetrabromide.1. J. Am. Chem. Soc. 1921, $43(4), 938-940$.

(34) O’Connor, R. T.; Heinzelman, D. C.; McKinney, R. S.; Pack, F.; C. The spectrophotometric determination of the alpha and beta isomers of eleostearic acid in tung oil. J. Am. Oil Chem. Soc. 1947, 24 (6), 212-216.

(35) Durand, E.; Zhao, Y.; Coupland, J. N.; Elias, R. J. Assessing Interactions between Lipophilic and Hydrophilic Antioxidants in Food Emulsions. J. Agric. Food Chem. 2015, 63 (49), 10655-10661.

(36) El Alaoui, M.; Noiriel, A.; Soulère, L.; Grand, L.; Queneau, Y.; Abousalham, A. Development of a High-Throughput Assay for Measuring Phospholipase A Activity Using Synthetic 1,2- $\alpha$-Eleostearoyl- $s n$-glycero-3-phosphocholine Coated on 
Microtiter Plates. Anal. Chem. 2014, 86 (21), 10576-10583.

(37) Brauer R.W., Steadman L. T. The autoxidation of $\beta$-eleostearic acid: the application of the spectrophotometer to the study of the course and the kinetics of the reaction. J. Am. Chem. Soc. 1944, 66, 563-569.

(38) Prior, R. L.; Wu, X.; Schaich, K. Standardized methods for the determination of antioxidant capacity and phenolics in foods and dietary supplements. J. Agric. Food Chem. 2005, 53 (10), 4290-4302.

(39) Soobrattee, M. A.; Neergheen, V. S.; Luximon-Ramma, A.; Aruoma, O. I.; Bahorun, T. Phenolics as potential antioxidant therapeutic agents: Mechanism and actions. Mutat. Res. Mol. Mech. Mutagen. 2005, 579 (1-2), 200-213.

(40) Apak, R.; Özyürek, M.; Güçlü, K.; Çapanoğlu, E. Antioxidant Activity/Capacity Measurement. 1. Classification, Physicochemical Principles, Mechanisms, and Electron Transfer (ET)-Based Assays. J. Agric. Food Chem. 2016, 64 (5), 997-1027.

(41) Rice-Evans, C. A.; Miller, N. J.; Paganga, G. Structure-antioxidant activity relationships of flavonoids and phenolic acids. Free Radic. Biol. Med. 1996, 20 (7), 933-956.

(42) Durand, E.; Jacob, R. F.; Sherratt, S.; Lecomte, J.; Baréa, B.; Villeneuve, P.; Mason, R. P. The nonlinear effect of alkyl chain length in the membrane interactions of phenolipids: Evidence by X-ray diffraction analysis. Eur. J. Lipid Sci. Technol. 2017, 118. DOI: 10.1002/ejlt.201600397. 


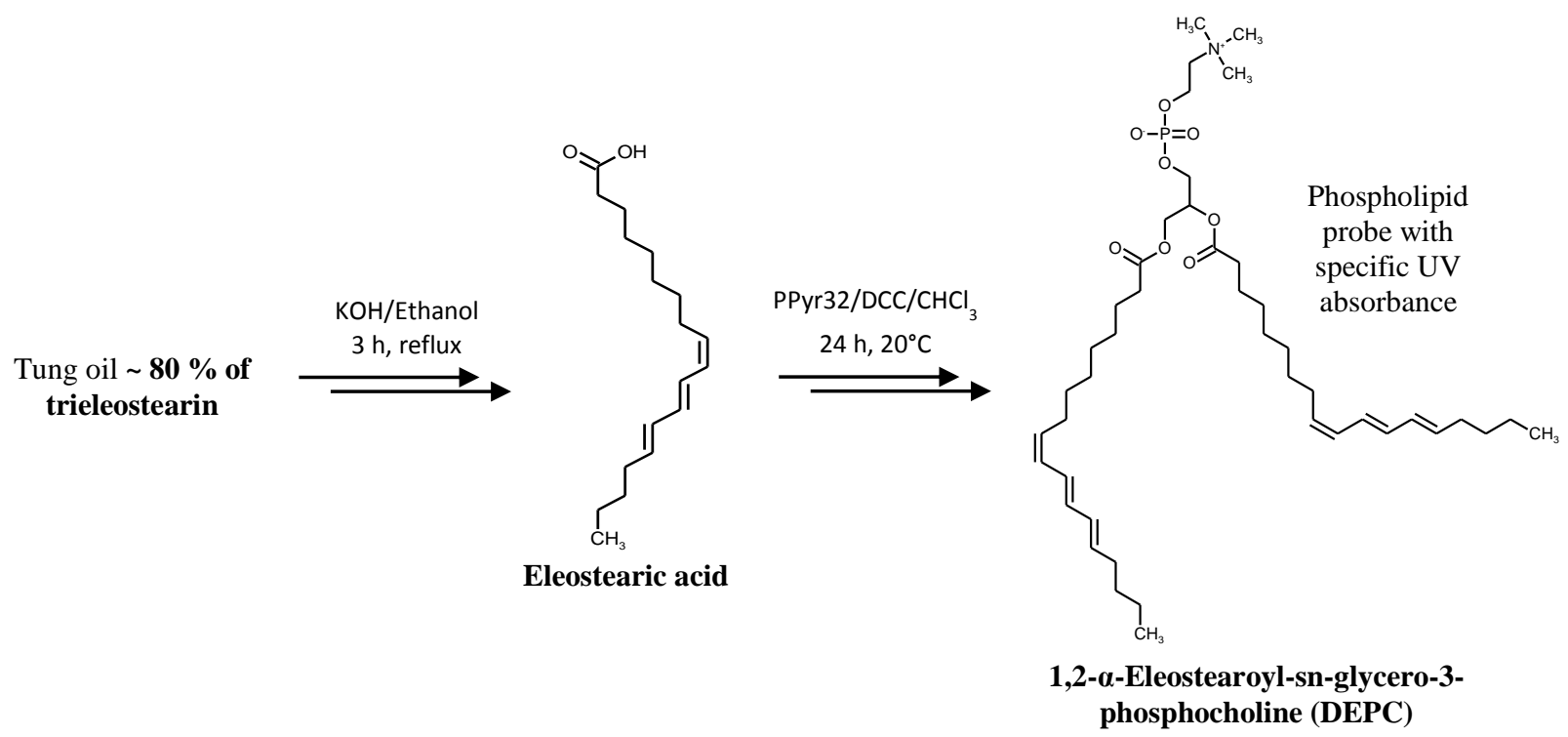

Figure. 1: Synthesis pathway of the 1,2- $\alpha$-Eleostearoyl-sn-glycero-3-phosphocholine (DEPC) probe.

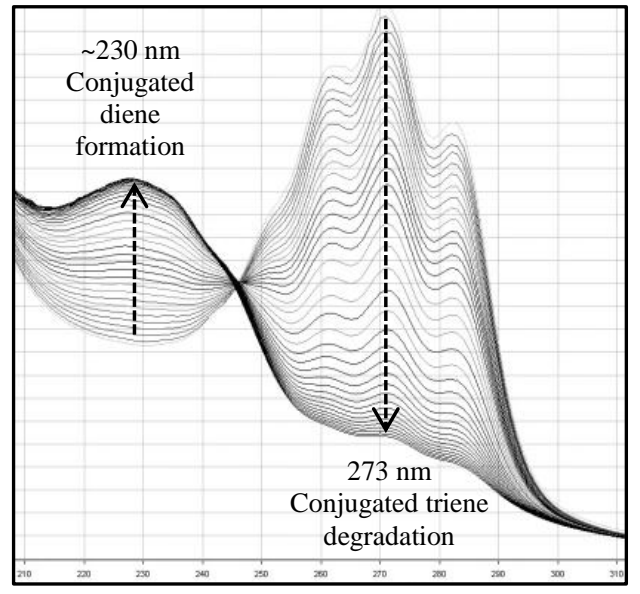

Figure. 2: UV signal of DEPC probe in DLPC membrane (1:10, w:w), and monitoring of its oxidation induced by $1 \mathrm{mM}$ of $\mathrm{AAPH}$ at $40^{\circ} \mathrm{C}$. 

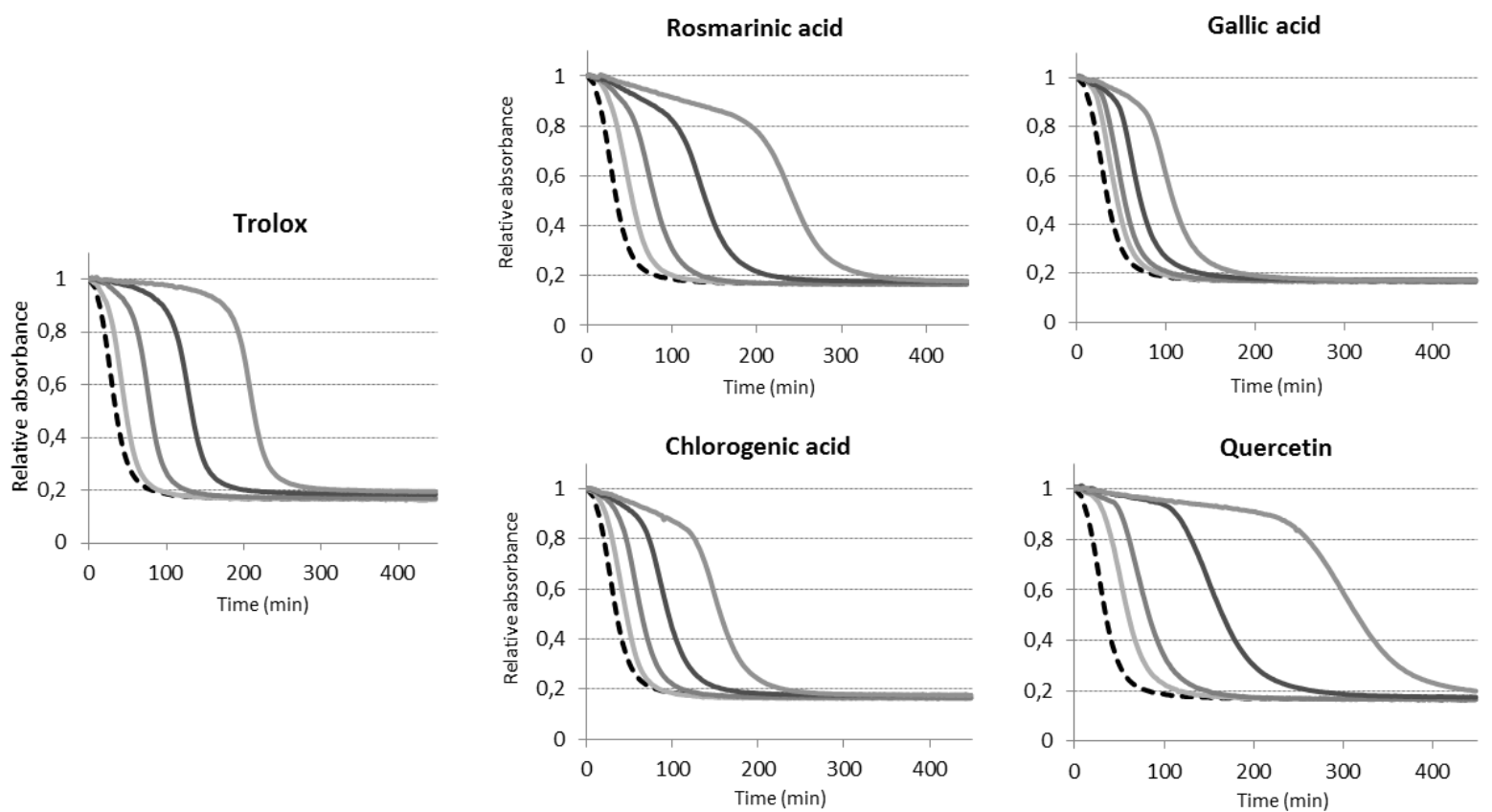

Figure 3: Kinetics of relative absorbance decay in the absence and presence of various amounts of antioxidants. The liposome suspension was made with DEPC/DLPC (1:10, w:w ratio) in PBS, pH 7.2, at $34.5 \pm 0.5{ }^{\circ} \mathrm{C}$ and contained AAPH $(2 \mathrm{mM})$ without $(---)$ and with (-) an antioxidant: Trolox $(0.5$ to $8 \mu \mathrm{M})$; or gallic acid $(0.5$ to $4 \mu \mathrm{M})$; or rosmarinic acid $(0.2$ to $2 \mu \mathrm{M})$; or chlorogenic acid $(0.2$ to 2 $\mu \mathrm{M})$; or quercetin $(0.5$ to $4 \mu \mathrm{M})$.
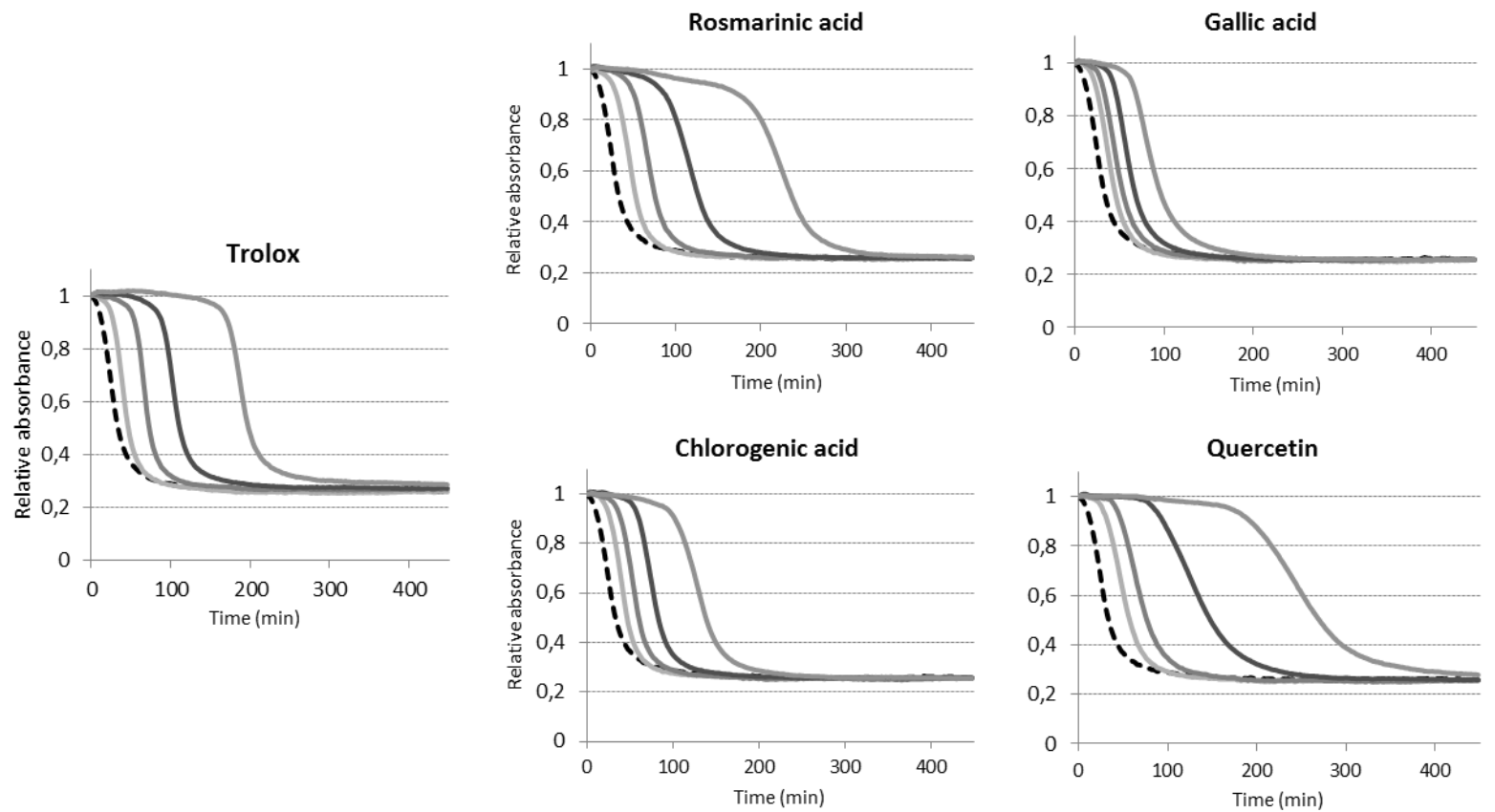
Figure 4: Kinetics of relative absorbance decay in the absence and presence of various amounts of antioxidants. The liposome suspension was made with DEPC/DLPC (1:10, w:w ratio) in PBS, pH 7.2, at $34.5 \pm 0.5{ }^{\circ} \mathrm{C}$ and contained AAPH $(2 \mathrm{mM})$ without $(---)$ and with $(-)$ an antioxidant: Trolox $(0.5$ to $8 \mu \mathrm{M})$; or gallic acid $(0.5$ to $4 \mu \mathrm{M})$; or rosmarinic acid $(0.2$ to $2 \mu \mathrm{M})$; or chlorogenic acid $(0.2$ to 2 $\mu \mathrm{M})$; or quercetin $(0.5$ to $4 \mu \mathrm{M})$.

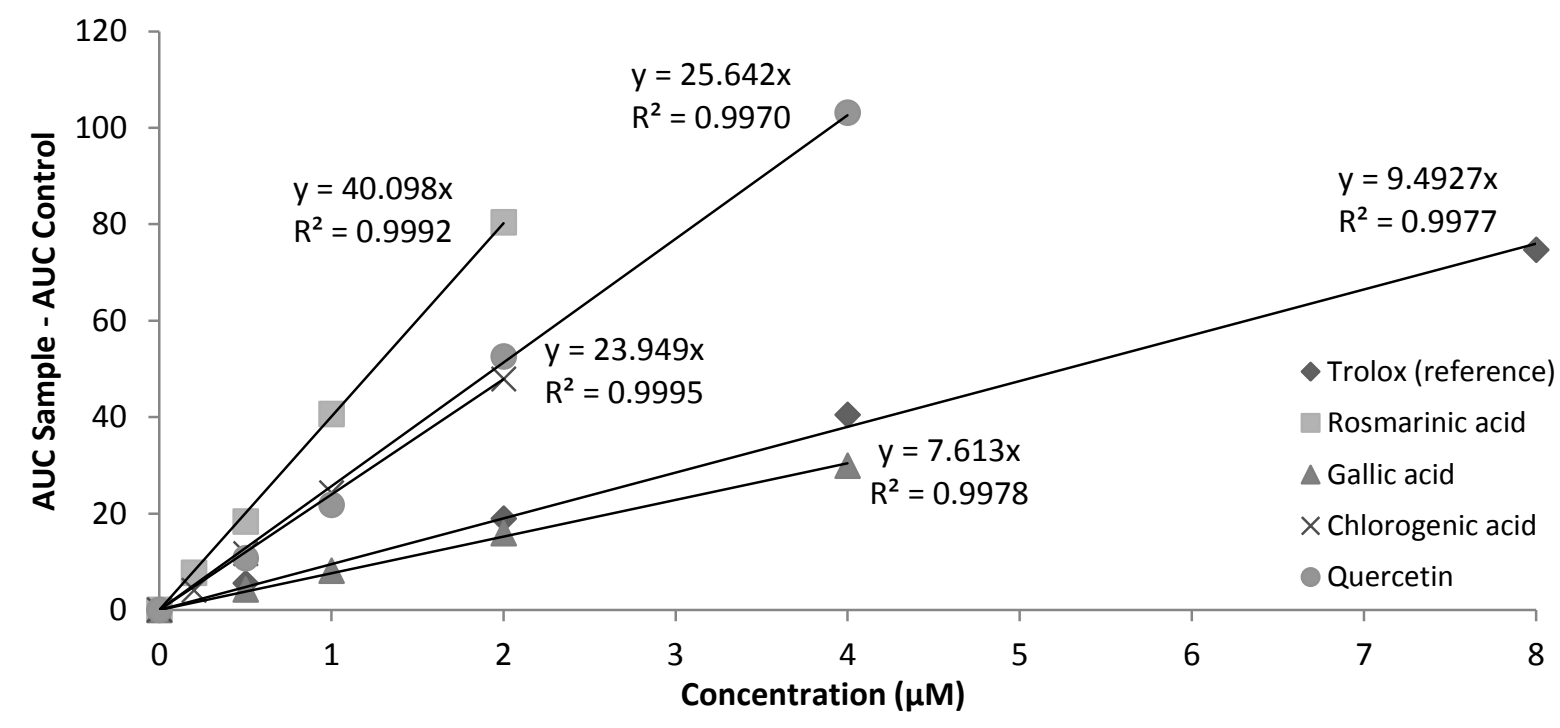

Figure 5: Net protection $\mathrm{AUC}\left(\mathrm{AUC}_{\text {Sample }}-\mathrm{AUC}_{\mathrm{Control}}\right)$ versus concentration for five different antioxidants (including Trolox as reference), in VesiCAT-AAPH assays made with DEPC/DLPC (1:10, w:w ratio), in PBS, $\mathrm{pH} 7.2$, at $34.5 \pm 0.5^{\circ} \mathrm{C}$.

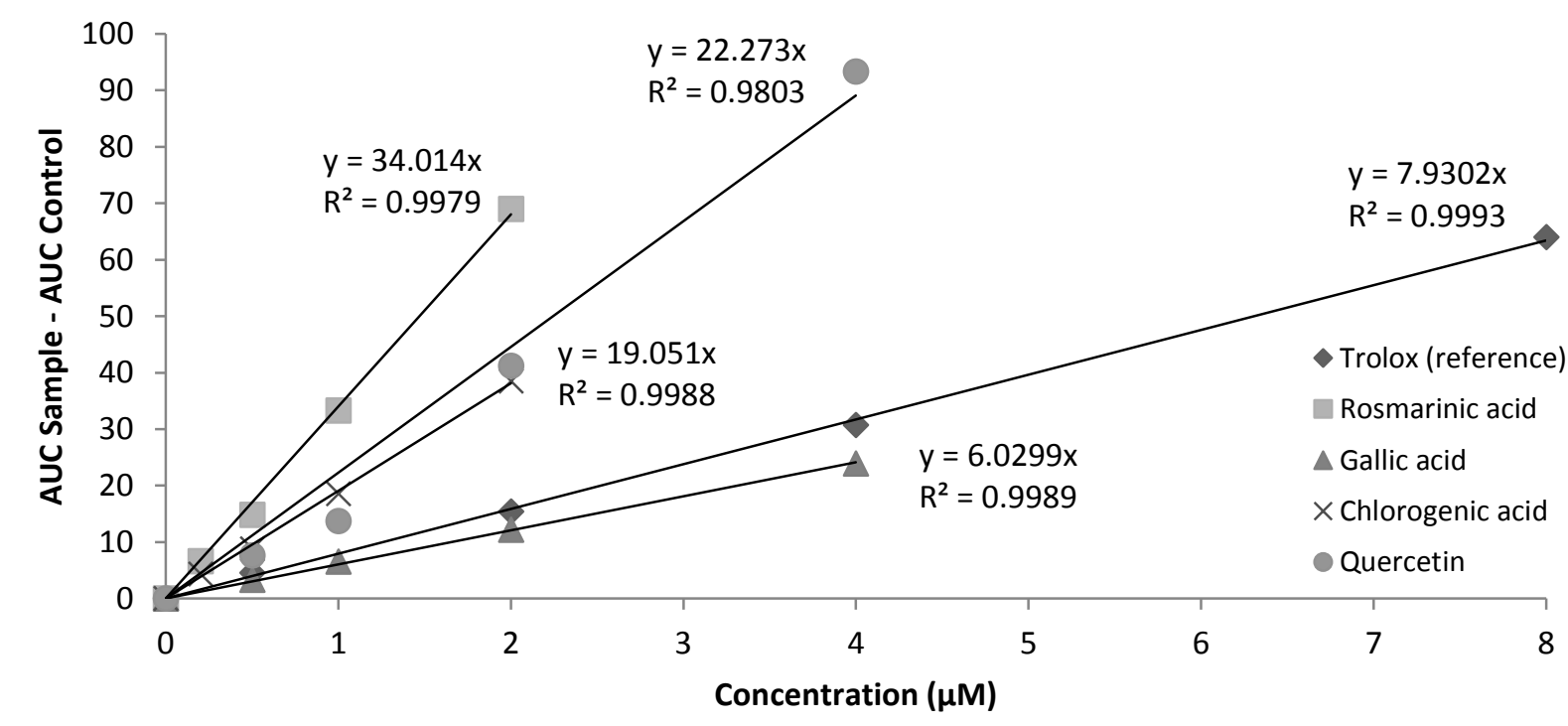


Figure 6: Net protection $\mathrm{AUC}\left(\mathrm{AUC}_{\text {Sample }}-\mathrm{AUC}_{\mathrm{Control}}\right)$ versus concentration for five different antioxidants (including Trolox as reference), in VesiCAT-AAPH assays made with DEPC/DPPC (1:10, w:w ratio), in PBS, $\mathrm{pH} 7.2$, at $34.5 \pm 0.5^{\circ} \mathrm{C}$.
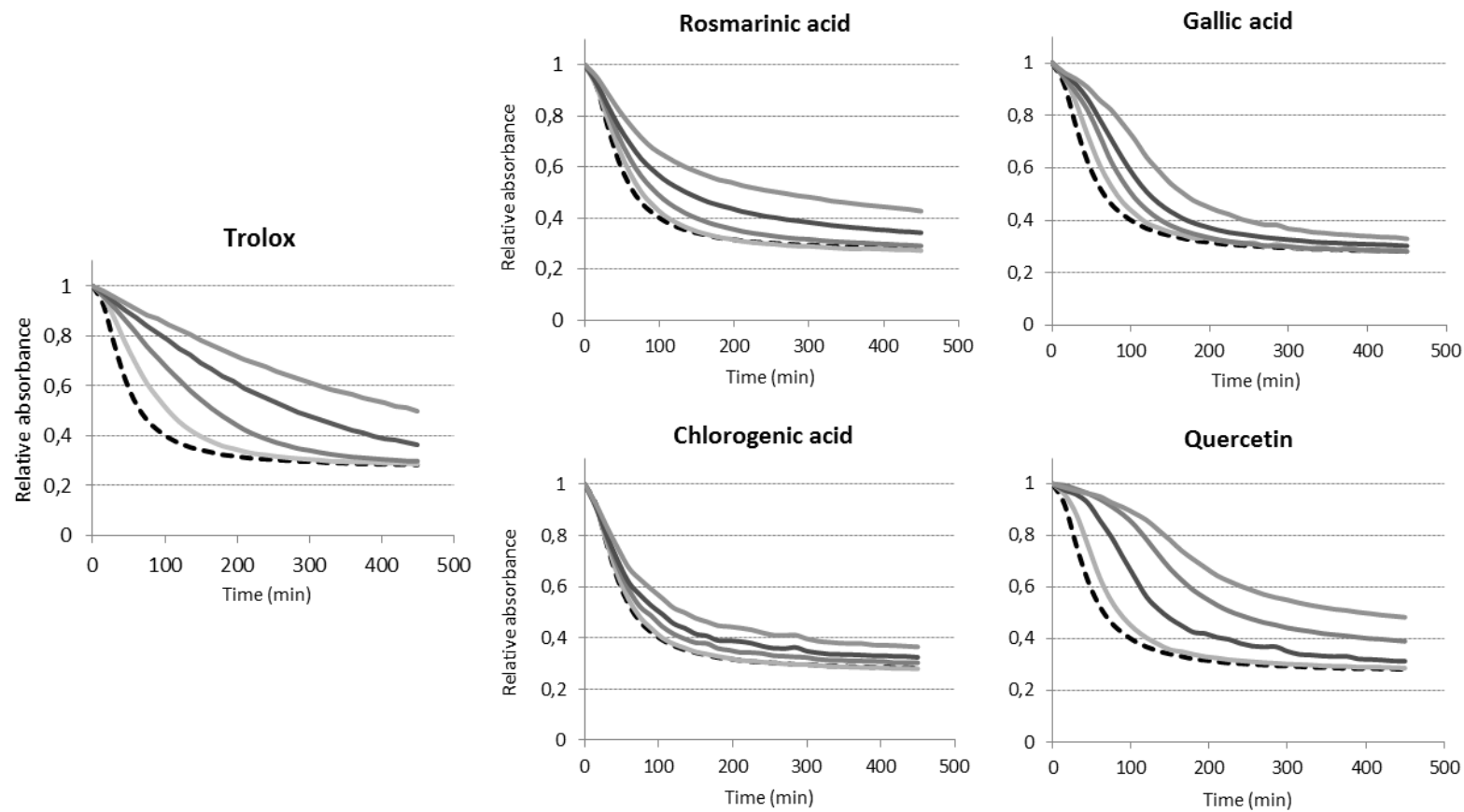

Figure 7: Kinetics of relative absorbance decay in the absence and presence of various amounts of antioxidants. The liposome suspension was made with DEPC/DLPC (1:20, w/w) in PBS, pH 7.2, at 43 $\pm 0.5^{\circ} \mathrm{C}$ and contained AMVN $(0.3 \mathrm{mM})$ without (- - ) and with (-) an antioxidant: Trolox $(0.5$ to 5 $\mu \mathrm{M})$; or gallic acid (1 to $20 \mu \mathrm{M})$; or rosmarinic acid $(0.5$ to $6 \mu \mathrm{M})$; or chlorogenic acid (1 to $20 \mu \mathrm{M})$; or quercetin (1 to $9 \mu \mathrm{M})$. 


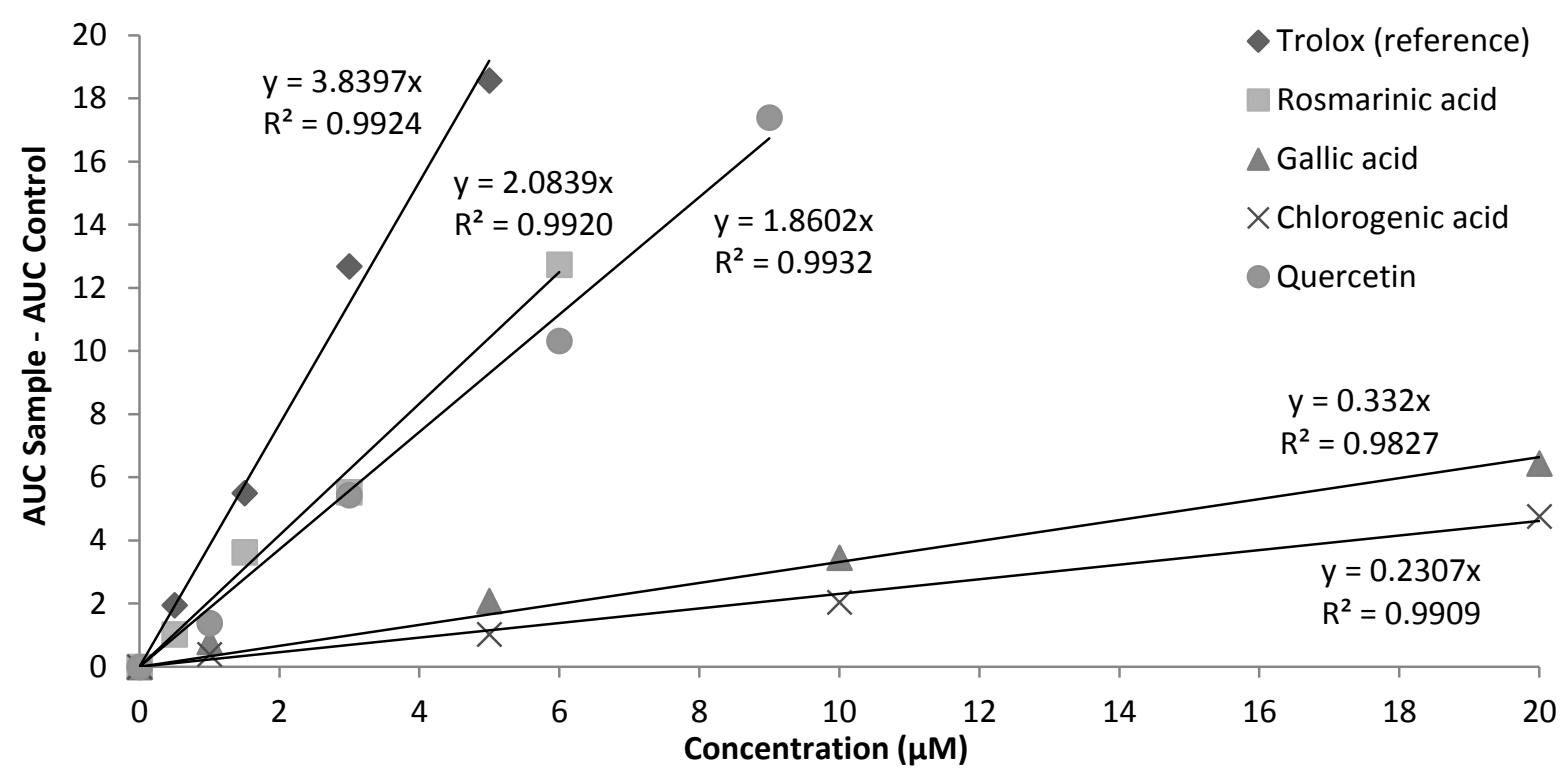

Figure 8: Net protection $\mathrm{AUC}\left(\mathrm{AUC} \mathrm{C}_{\text {Sample }}-\mathrm{AUC}_{\mathrm{Blank}}\right)$ versus concentration for five different antioxidants (including Trolox as reference), in VesiCAT-AMVN assays made with DEPC/DLPC (1:20, w:w), in PBS, $\mathrm{pH} 7.2$, at $43 \pm 0.5^{\circ} \mathrm{C}$. 
Table 1: Comparison of the antioxidant values obtained with the VesiCAT assays, expressed as Trolox equivalents (TE) of four pure phenolic compounds. All measurements were performed in triplicate VesiCAT assays and reported as the average \pm standard deviation (SD).

\begin{tabular}{|c|c|c|c|c|c|}
\cline { 3 - 6 } \multicolumn{2}{c|}{} & \multicolumn{4}{c|}{ VesiCAT Values (TE) } \\
\hline \multirow{2}{*}{ Assays } & Rosmarinic acid & Gallic acid & Chlorogenic acid & Quercetin \\
\hline \multirow{2}{*}{$A A P H$} & $D E P C / D L P C$ & $4.13 \pm 0.13$ & $0.93 \pm 0.22$ & $2.62 \pm 0.26$ & $2.63 \pm 0.58$ \\
\cline { 2 - 6 } & $D E P C / D P P C$ & $4.27 \pm 0.02$ & $0.78 \pm 0.04$ & $2.41 \pm 0.01$ & $2.92 \pm 0.16$ \\
\hline \multirow{2}{*}{$A M V N$} & $D E P C / D L P C$ & $0.549 \pm 0.007$ & $0.107 \pm 0.029$ & $0.084 \pm 0.033$ & $0.486 \pm 0.002$ \\
\hline
\end{tabular}

